It will be seen that three of the cases were under forty and two under forty-five. Except for one case, the length of history was measured in years. Seven of the eight ulcer-cancers occurred in the pyloric antrum, thus confirming that it is the chronic ulcer in this situation which is particularly liable to undergo malignant change. Five of the patients are dead, one was dying when last seen and two are still alive and well, but these were operated on within the last 18 months.

From the present series, therefore, it may be concluded that it is rare for a chronic gastric ulcer to undergo malignant change, but that it does occur there can be no doubt. The prognosis is extremely bad.

\section{BIBLIOGRAPHY}

ASKANAZY M. (1920), Rev. méd. de la Suisse Romande, 40, 477. ASKANAZY, M. (1924), Virch. Arch., 250, 370.

BOCKUS, H. L. (1946), 'Gastro-enterology,' Vol. I, p. 364. Saunders.

DIBLE, J. H. (1925), Brit. Ұ. Surg., 12, 666.

HURST, A. F., and STEWART, M. J. (1929), 'Gastric and Duodenal Ulcer,' Oxford University Press.

NEWCOMB, W. D. (1932-33), Brit. F. Surg., 20, 279.

SWYNNERTON, B. F., and TANNER, N. C. (1953), Brit. med. 7 ., है ii, 84r.

WILSON, L. B., and MCCARTHY, W. C. (1910), Amer. F. Med. $\vec{\circ}$ Sci., 138, 846 .

\title{
THE ACUTE COMPLICATIONS OF PEPTIC ULCER AND THEIR SURGICAL TREATMENT
}

\author{
By A. G. R. Lowdon, O.B.E., F.R.C.S.E. \\ From the Department of Surgery, University of Edinburgh
}

Perforation and haemorrhage, the acute complications of peptic ulcer, are of importance mainly because they may be the cause of death in a disease which otherwise does not usually threaten the life of the patient; these complications are also of special interest at the present time because the views of physicians and surgeons about their treatment have recently changed and are, indeed, still undetermined.

\section{Perforation}

The term 'perforation' is used to describe the free perforation of a peptic ulcer into the peritoneal cavity in distinction to the 'penetration' which occurs when an ulcer invades a neighbouring organ such as the pancreas.

Perforation occurs most commonly in ulcers on the anterior surfaces of duodenum or stomach, but occasionally a posterior ulcer perforates freely into the lesser sac. Perforation may also occur in a gastrojejunal ulcer or in an ulcer related to Meckel's diverticulum, and an oesophageal peptic ulcer may perforate into the pleural cavity. The simultaneous perforation of two ulcers has been reported.

Most perforated ulcers are of a chronic type, but the complication may occur in relatively acute ulcers which have been present for at most one or two weeks (Fig. I).

\section{Incidence}

Because perforation of a peptic ulcer almost $\bar{\partial}$ invariably leads to admission to hospital and to accurate diagnosis, studies of the frequency of the $\stackrel{\mathbb{Q}}{\propto}$ complication are comparatively reliable. In the $\overrightarrow{\vec{P}}$ I9th century perforation was an uncommon event $\frac{3}{3}$ and the majority of cases occurred in young women (Brinton, 1857), but a remarkable change of the incidence has occurred since the first decade of this century (Stewart and Winser, 1942; Tidy, $\underline{3}$. 1945). Perforation is now relatively common and occurs much more frequently in men-about 15 men to one woman. It may occur at any age, but $\delta$ is rare before adolescence; it is most frequent 3 between 30 and 45 years, but it is now not un- 을 common in the aged. The perforation of an ulcer $\rightarrow$ does not appear to be related in time to the eating of food or to physical exertion. There is more danger of the complication when the patient is $\Omega$ physically or mentally tired; the incidence of $N$ perforation rises in the winter months, at the end of the working week and at the end of the working 0 day (Illingworth et al., 1944; Jamieson, 1947).

\section{The Clinical Features of Perforation}

The typical clinical picture of an acute perforation in a patient who gives a history of peptic ulcer symptoms is easily recognized from the 


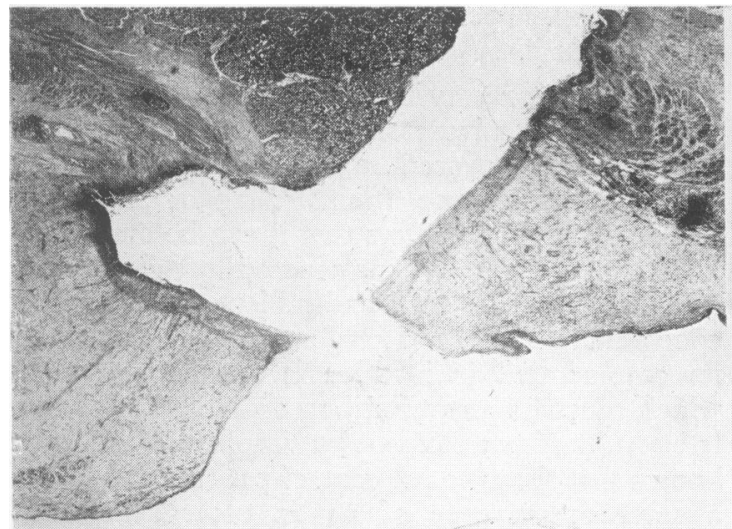

Fig. I.-Photomicrographs of sections of two perforated ulcers. (a) A chronic ulcer as shown by extensive subserous fibrosis and obliterative endarteritis; there is in addition evidence of recent activity in zones of necrosis and granulation.

history of sudden onset of agonizing pain and the finding of a rigid and acutely tender abdomen. Sometimes, however, the escape of bowel content is limited, as may occur when the stomach is nearly empty, when the opening is small, or when there is early spontaneous sealing of the opening by adhesions or even blocking of the hole by a large particle of food. The symptoms and signs may then be less severe and there may be difficulty in establishing the diagnosis. When minimal escape has occurred the signs may be quite localized; the description of 'leaking ulcer' is often applied to this type of case. If physical signs are relatively localized to the right upper quadrant of the abdomen there may be confusion with acute cholecystitis. The soiling from a perforation in the pyloric region tends to track downwards over the transverse colon and the omentum into the right lower quadrant of the abdomen (Mitchell, “1940), and the pain and tenderness may appear to be maximal in the right iliac fossa, leading to confusion with appendicitis. Acute pancreatitis and coronary thrombosis are other important sources of confusion.

In doubtful cases a detailed history is of great help, but the clinician must remember that between Io and 15 per cent. of perforations occur in patients who have not had previous dyspepsia of the ulcer type. The patient usually lies supine and immobile, afraid of movement, but there are exceptions even to this traditionally characteristic feature, because an occasional patient will throw himself about in his agony or sit upright and refuse to lie down. One of the most helpful findings on examination is the detection of free gas in the peritoneal cavity. The quantity of gas may be

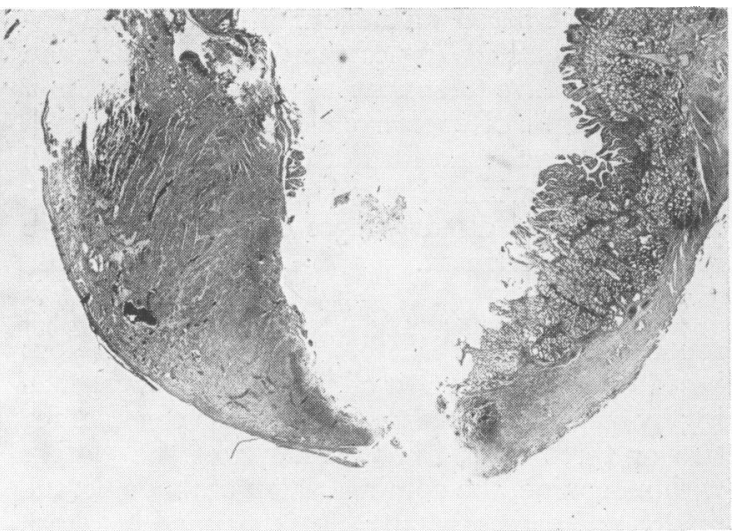

(b) A relatively acute ulcer with absence of subserous fibrosis and obliterative endarteritis; under the necrotic zone is a minimal granulation tissue reaction. $(\times 6)$

small and the clinical sign of loss of liver dullness is only rarely helpful, but even a small quantity of gas can be demonstrated under the diaphragm by $\mathrm{X}$-ray examination with the patient in the sitting posture, or in the right flank with the patient lying on his left side. Radiological examination should be made in any doubtful case; the finding of gas is almost conclusive, but the sign is absent in about 20 per cent. (Olson and Norgore, 1946).

Serum and urinary amylase estimations may help in the diagnosis of acute pancreatitis, but it should be remembered that in perforation some escape and absorption of pancreatic secretions may occur and lead to a moderate rise of these concentrations. If coronary thrombosis is seriously considered, a delay of a few hours, after sedation, to observe progress and get an electrocardiogram carries less risk than an ill-advised operation.

\section{The Treatment of Perforated Ulcer}

For more than 50 years it has been the established practice to treat perforated peptic ulcer by operative closure of the perforation. In this time the only. important change of technique has been the abandonment of suprapubic drainage of the pelvis, which was formerly routinely employed in all but early cases.

The immediate mortality of perforation when treated by simple closure has fallen rapidly in the last 10 years. Before 1940 an average mortality was 20 per cent., but more recent reports have shown that it is now possible to keep the death rate down to about 5 per cent. This improvement must be ascribed to advances in anaesthesia, resuscitation, fluid and electrolyte control and chemotherapy.

In more recent years two alternative methods of treatment have been advocated: conservative 
management based on measures designed to encourage natural sealing of the opening, and more radical operative treatment by partial gastrectomy. The technique of operative closure is well enough known to require no further description here and consideration will be limited to presentation of the advantages and disadvantages of these alternative methods of treatment.

The conservative method was first advocated as a routine measure by Bedford-Turner (1945). It is based on the prevention of further peritoneal soiling by continuous aspiration of gastric contents for two or three days, initial sedation of the patient with morphine, the administration of fluids parenterally and chemotherapy. It is claimed by those who employ this method of treatment that the resulting mortality rate is at least no higher than that which follows routine operation. The advantages are that the patient is not subjected to laparotomy and can return to work, on the average, in less than half the time required for convalescence after operation (Heslop et al., 1952). Perhaps the most obvious theoretical objection to this method of management is the notorious difficulty of keeping the stomach empty by aspiration. It has been given a trial by many surgeons, but is recommended by few; even those who have supported it emphasize the difficulties involved. It is not suitable for any case of gastric perforation or when peritoneal soiling is massive. It should not be employed when there is doubt about the diagnosis or when the perforation is complicated by haemorrhage. When it has been adopted at the outset in the treatment of a case it should be abandoned in favour of operation if pain is not rapidly relieved or if gastric aspiration is ineffective as judged by the quantities removed, by X-ray control of the position of the tube in the stomach and by X-ray control of the extent of pneumoperitoneum. It requires the constant vigilant supervision of an experienced clinician.

On the whole, there can be little doubt that the disadvantages of the conservative procedure heavily outweigh the advantages. The lesson to be learned from its use is that gastric aspiration can discourage further peritoneal soiling and can promote spontaneous sealing. Gastric suction may be life-saving in circumstances which make operative treatment impracticable, as in a snow-bound cottage or on board a ship. It is to be hoped, too, that we shall soon see the day when every general practitioner will carry a small gastric tube and will use it to empty the stomach of any patient who perforates soon after a meal or who will, because of distance or other factors, take several hours to reach a hospital. In hospital conservative measures are to be preferred only when it is confidently judged that any small perforation has already sealed off spontaneously.

Partial gastrectomy in the treatment of perforat ulcer was first advocated by Yudin (1937) and is now a routine procedure in many parts of the continent of Europe (Samain, I950; Nuboe? 1951). Experience shows that it can be employed with surprising safety provided the selection of cases excludes the aged and patients with seriogs concomitant disease (Lowdon, 1952). Whether its employment is justified is another question which must be answered by consideration of the late results after treatment by simple closure. It is known that about $5 \circ$ per cent. of patients will suffer a severe recurrence of peptic ulcer symptorgs within five years of a perforation treated by closufe (Illingworth et al., I946; Gilmour, I953), and may be concluded that most, if not all, of these patients would benefit from the more radicid treatment. The problem is to select the cases with bad prognosis.

Partial gastrectomy as a primary procedure $\dot{\mathbf{m}}$ the treatment of perforation has as yet had onlya limited trial in this country, but it will probably employed more frequently when the indicatio are more clearly defined. At present it may be concluded that it should be considered, if congr $\vec{b}$ indications are absent, in the following circump stances: When the perforation is in a gastric 诿e (other than an evidently acute prepyloric ulçer $\$$ when the perforation is complicated by haemorhage; when there has been a previous perforation; when there is evidence of pyloric stenosis; when the perforation culminates a long period of ulcer dyspepsia. It should not be considereal unless the surgeon and his team are experienced the operation of gastrectomy.

\section{Haemorrhage}

In considering haemorrhage from a peptic ulcew, distinction must be made between occult bleeding and manifest bleeding in the form of haematemesis or frank melaena. Manifest bleedings, with which we are here concerned, have a wide range of severity. The loss of less than $100 \mathrm{ml}$. of blood from the ulcer may give rise to obvious blood the vomitus or to a black stool (Daniel and Egan 1939); in such a case there may be no apparefit systemic upset. At the other extreme are cases which two $0:$ three litres of blood are rapidly lost from a large vessel and the patient is profoundty shocked and exsanguinated. Attempts have been made to classify the degrees of manifest haemof rhage as slight, moderate and massive, but the criteria are necessarily arbitrary and have led to more confusion than clarification in the con parison of results of treatment. 


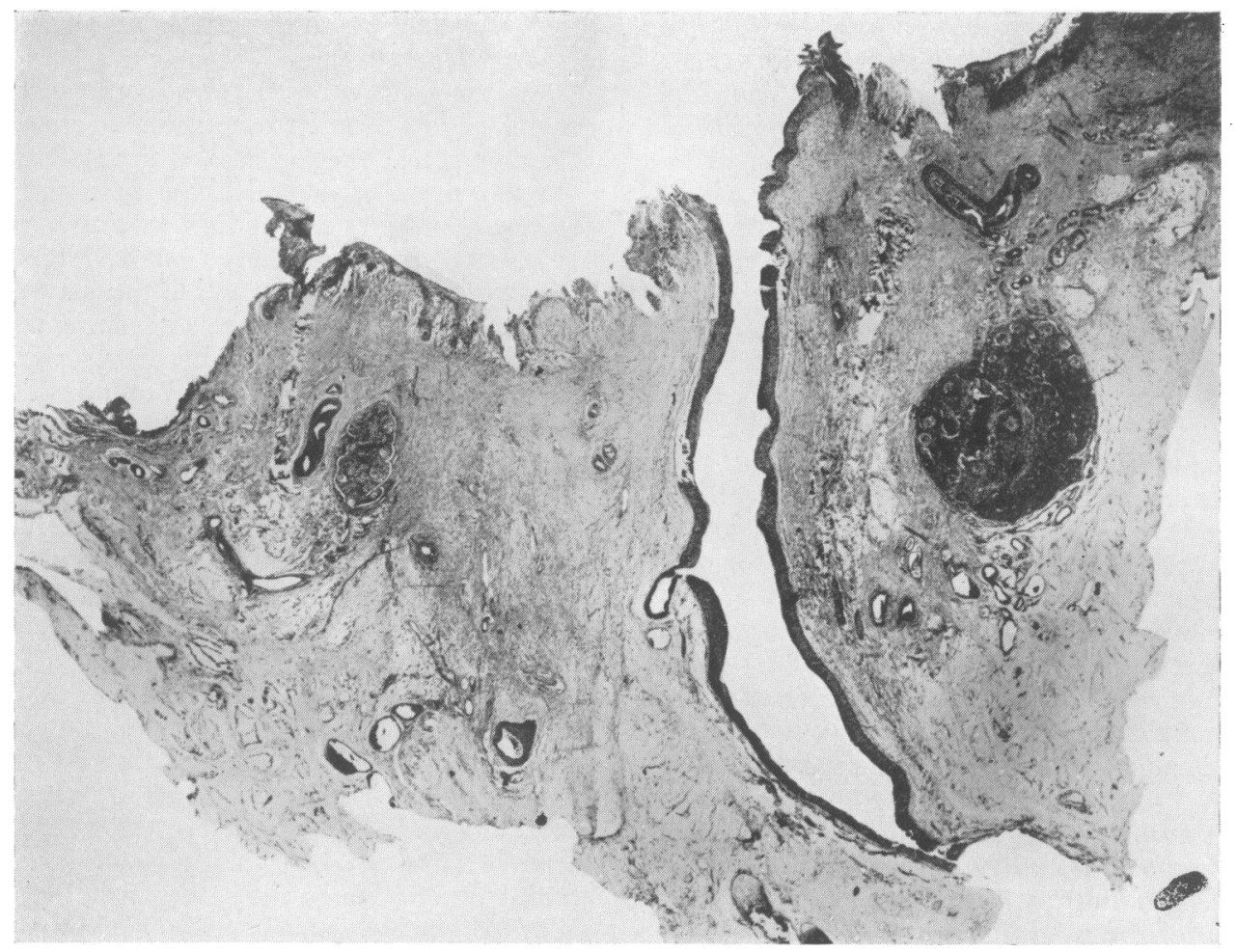

FIG. 2.-Photomicrograph of a section of a gastric ulcer removed at emergency partial gastrectomy for massive haemorrhage. A large vessel opens on to the ulcer base where its natural closure is prevented by the surrounding chronic inflammatory tissue. $(\times 6)$

\section{Incidence and Mortality}

Published reports of the incidence and mortality of the complications are very variable, but Ivy et al. (I95I) have levelled out some of these discrepancies by making a review of more than 23,000 collected cases. They conclude that manifest bleeding occurs, sooner or later, in about 25 per cent. of patients with peptic ulcer, and that about 7.5 per cent. of bleeding ulcers have proved fatal. Men and women patients are equally liable to have a haemorrhage, but the risk of bleeding increases with age. Gastrojejunal ulcers are most liable to bleed, and gastric ulcers bleed more readily than duodenal ulcers.

\section{The Selection of Cases for Surgical Treatment}

Since the pioneer work of Gordon-Taylor (1934, 1935) in this field it has been generally accepted that some patients with bleeding peptic ulcers should be treated by emergency operation. The criteria by which these cases are to be selected are still, however, ill-defined.

The selection should be made by physician and surgeon together, preferably under circumstances which allow both to be in touch with the problem from the time of the admission of the patient to hospital. Having excluded, as far as possible, all cases of gastroduodenal bleeding due to causes other than peptic ulcer, they must attempt to select the patients in whom the risk to life under continued medical treatment is greater than the risk of immediate surgery. The factors involved are so numerous and so difficult to assess that it is not possible to define categorically the type of case that should be treated by emergency operation. It will be profitable, however, to mention the main factors which must be considered.

The prognosis under continued medical treatment is affected adversely by the following features :

Age over 50 years. This is an arbitrary dividing line, but it is clear that the mortality rises with age, and bleeding is more likely to continue or recur in older persons.

Continued or recurrent bleeding under treatment. This clinical feature is generally agreed to be associated with poor prognosis if medical treatment is continued and to be the most pressing indication for emergency surgery.

Gastric ulcer. The mortality from bleeding 
gastric ulcer is approximately double that of bleeding duodenal ulcer. The site of the bleeding ulcer is not always known, but if there should be evidence that it is in the stomach the decision to treat by operation should be the more readily made.

Massive bleeding or severe haemorrhagic shock. If the clinical evidence, more particularly the general condition of the patient, shows that the blood loss is both large and rapid, it is probable that the bleeding is from a relatively large vessel. Under these circumstances, emergency surgery should be the more readily and the more promptly undertaken. It must be appreciated that some of the more massive haemorrhages occur from terminal or lateral openings in large arteries which are unlikely to stop bleeding by natural means (Fig. 2).

It is to be noted that a second or subsequent haemorrhage is not any more dangerous than a first episode of bleeding, provided that the patient has recovered from the previous blood loss. It is sometimes said that the persistence of pain after bleeding heralds a bad prognosis, but the writer has been unable to confirm this in a survey of 355 cases.

The risks of operation which have to be put against these considerations are equally difficult to assess. Severe haemorrhagic shock will never by itself be a contraindication to operation, because it can be combated by rapid and adequate blood transfusion-if need be, after arrest of the active bleeding on the operating table. On the other hand, if the state of anaemia, dehydration and under-nutrition which commonly follows a severe haemorrhage is allowed to persist for more than 24 to 48 hours, the patient becomes a poor surgical risk. This is a fundamental observation, supported by experience as well as theory, and leads us to practical conclusions :

In any case of continued bleeding, if surgical intervention is to carry a reasonable hope of success, it should be decided on early and carried out promptly. If the patient has been ' too low for too long,' operation may seal his fate rather than improve his chances of recovery. If a recurrence of bleeding after an interval is to be accepted as an indication for emergency surgical measures, it is most desirable that the patient should not have spent the intervening days in a depleted state. If surgical intervention is to remain a practical possibility, the conservative treatment should include prompt and liberal transfusion of blood.

The patient's age and general physical condition, including any associated but unrelated disease, must also be considered. It cannot be too strongly emphasized, however, that the object is not to select for surgery a series of good risk patients. The results of surgical treatment cannot be judged by operative mortality: 15 deaths in 20 operations may represent five livès sàved if all 20 would have died without surgery.

On the basis of such considerations, each case may be judged on its own merits, some accepted for emergency surgery at the time of admission, others treated conservatively at first, and brought to operation only if bleeding continues or recurs. It is, however, desirable for any hospital to have a 'policy' even if only to guide the junior medical and nursing staff, so that developments which may call for immediate surgical intervention are not overlooked until the next ward round. The policy adopted must depend on local circumstances and individual views, but examples may be quoted.

Tanner and Desmond (1950) have published a valuable report of the results of different methods of dealing with the problem. They found that their overall mortality was lowest ( 7 per cent.) when the dictates of Finsterer (1947) were followed, i.e. immediate operation for all patients with massive haemorrhage and a known chronic ulcer, and later operation on the others if bleeding recurs or persists. In this period, however, they found that 60 per cent. of all patients admitted with manifest bleeding were treated by operation; this represents a surgical undertaking which will not be found practicable in many hospitals. The policy adopted by Ogilvie et al. (1952) is more generallys applicable; they report a series of $35^{8}$ cases of bleeding in which the decision to operate was made if at the end of 24 hours of hospital treatment bleeding was continuing, or if bleeding, having once stopped, started again. On these indications operation was carried out in ro per cent. of their cases and the overall mortality was 5 per cent.

It is worthy of note that both these series are reported with quotation of the overall mortality only: the results of the groups treated by surgery are not given. Both papers give the proportion of patients over 60 years of age in the series, because this is a measurable factor which is bound to influence the results. In Tanner's series 42 per cent. and in the Newcastle series 30 per cent. were over 60 years of age.

\section{The Surgical Management of Bleeding Ulcer}

When a decision to treat the patient by emergency operation has been made there should be as little delay as possible. Immediately before operation, and preferably in the anteroom of the theatre, blood transfusion is speeded up so that the patient comes to operation in the best possible condition. Rarely the failure to respond even to rapid transfusion shows that bleeding is continuing so actively that laparotomy to arrest the haemorrhage is needed before resuscitation can be effective.

Anaesthesia may be local or general; in either case a small stomach tube should be passed and all 
precautions taken against the risk of further vomiting.

The laparotomy incision must give good exposure. Examination of the organs will usually give ready confirmation of the presence of a chronic peptic ulcer and the absence of other causes of gastroduodenal bleeding, but in a disturbingly large minority of cases the source of the bleeding may be difficult to find. If there is no obvious lesion in stomach or first part of duodenum, the gastrocolic ligament should be opened to permit careful examination of the posterior aspects. If the lesion is still not apparent, the surgeon must consider two probable sources of difficulty: a relatively acute gastric ulcer or multiple gastric erosions may elude the most careful examination of the outside of the stomach, or a duodenal ulcer may be located unusually far from the pylorus, even in the pre-ampullary region. If exhaustive search reveals no evidence of the causative lesion, and if the patient's condition is reasonably good, it is best to proceed with the operation of partial gastrectomy and to ensure by palpation of the inside of the duodenum after its division, and palpation and inspection of the inside of the gastric remnant, that no obvious source of bleeding remains.

Some surgeons advise that when the lesion is not apparent a gastroduodenotomy should be made to allow palpation and inspection of the mucosal surfaces; this procedure is sometimes successful, but on the whole its value is open to doubt.

If the ulcer is identified, it is desirable, if possible, to perform a partial gastrectomy, including resection of the ulcer. When the general condition of the patient and the absence of blood in the duodenum and upper jejunum give reason to believe that there is no active bleeding, the surgeon may follow his usual technique in performing the resection. Occasionally, when there is evidence that bleeding is active, a direct attack on the ulcer first by digital pressure and then by appropriate suture ligatures is required. If the ulcer has penetrated into the pancreas, the base must be left; if the bleeding point is not apparent in the edge which has been removed, the ulcer bed must then be underrun with silk sutures. The feeding vessels also should, as far as possible, be ligated and the ulcer bed left outside the reconstituted bowel.

In the case of a bleeding gastric ulcer the surgeon may adopt some less radical procedure, such as local resection of the ulcer or gastrotomy and the placing of silk sutures through the ulcer bed. Duodenotomy and suture ligature of a duodenal ulcer is less satisfactory; it may be just as difficult to close a duodenum in continuity as to close a duodenal stump and a gastro-enterostomy is usually required. It must be appreciated that there is considerable risk of recurrence of bleeding when an ulcer has been left in situ; the silk sutures through the ulcer bed cut out readily and may even be the cause of later bleeding from another vessel. The less radical procedures may, however, be justified when the patient is old and feeble or when the operator is not experienced in gastric surgery.

Few problems in emergency surgery are more challenging than that of the operative treatment of bleeding ulcer. The good management of these cases calls for judgment, courage and skill from surgeon, anaesthetist, assistants and nurses alike.

\section{BIBLIOGRAPHY}

BEDFORD-TURNER, E. W. (1945), Brit. med. $\mathcal{f}$., i, 457. BRINTON, W. (1857), ' Ulcer of the Stomach,' Churchill, London. DANIEL, W. A. (Jun.), and EGAN, S. (1939), f. Amer. med. Ass., II3, 2232.

FINSTERER, H. (1947), Wien. med. Wschr., i, 3.

GILMOUR, J. (1953), Lancet, i, 870.

GORDON-TAYLOR, G. (1934), Proc. R. Soc. Med., 27, 1524

GORDON-TAYLOR, G. (1935), Lancet, ii (CCXXIX), 8I I.

HESLOP, T. S., BULLOUGH, A. S., and BRUN, C. (1952), Brit. $\mathcal{F}$. Surg., 40, 52.

ILLINGWORTH, C. F. W., SCOTT, L. D. W., and JAMIESON, R. A. (1944), Brit. med. $\mathcal{F}$., ii, 617,655 .

ILLINGWORTH C. F. W., SCOTT, L. D. W., and JAMIESON, R.A. (1946), Ibid., i, 787.

IVY, A. C., GROSSMAN, M. I., and BACHRACH, W. H. (I95I), 'Peptic Ulcer,' Churchill, London.

JAMIESON, R. A. (1947), Brit. med. f., ii, 289.

LOWDON, A. G. R. (1952), Lancet, i, 1270.

MITCHELL, G. A. G. (1940), Brit. F. Surg., 28, 291.

NUBOER, J. F. (195I), Lancet, ii, 952.

OGILVIE, A. G., CARDOE, N., and BENTLEY, F. H. (1952), Brit. med. F., il, 304.

OLSON, H. B., and NORGORE, M. (1946), Ann. Surg., 124, 479. SAMAIN, A. (1950), Acta gastro-ent. belg., 13, 100.

STEWART, D. N., and WINSER, D. M. (1942), Lancet, 1, 259. TANNER, N. C., and DESMOND, A. M. (1950), Postgraduate MEDICAL JOURNAL, 26, 253.

TIDY, H. (1945), Brit. med. $\mathcal{F} .$, i, 3 I 9.

YUDIN, S. (1937), Surg. Gynec. Obstet., 64, 63. 